\title{
Sadomasochistic Desire
}

This paper attempts to promote the recognition of the sexualized social world of BDSM in philosophical and tropological perspective. BDSM and especially $\mathrm{S} / \mathrm{M}$ is hard to understand in its own, characteristic motivational perspective because such negative experiences as, say, pain and humiliation indicate aversion rather than attraction; hence we ask what kind of desire is this supposed to be. To cause pain to others is typically condemned. To cosset pain and suffering is said to be perverse. My main point is, we can better understand BDSM via its typical language and rhetoric, especially by paying attention to the key role of linguistic metonymy when we discuss the riddles of pain and pleasure. I conclude that, within some reasonable limits, BDSM as a type of consensual kinky sex is not vulnerable to the standard forms of criticism. ${ }^{1}$

\section{Kinky Sex}

Psychological, legal, and sociological issues are mainly outside the scope of this philosophical and tropological essay. ${ }^{2}$ Yet, the relevant problems of BDSM are begging for explanation. BDSM refers to (often organized) activities such as bondage, domination, discipline, submission, and sadomasochism. ${ }^{3}$ BDSM is what one may call a sexual diversion, "serious leisure," and sometimes even a life-style. ${ }^{4}$ It is often practiced in clubs and other social venues where the performers and their audiences can enjoy the show. Of course, BDSM also takes place privately. It is important to distinguish between BDSM proper,

1 This paper contains partially rewritten parts of my paper "The Language of Pain: A Philosophical Study of BDSM," SAGE Open 8 (2018), 1-9.

2 Tropology in rhetoric studies the use of tropes or figurative language. The present paper is related to my "A Philosophical and Rhetorical Theory of BDSM," Journal of Mind and Behavior 31/1 (2017), 53-74.

3 A useful Terms Dictionary can be found at https://www.bdsm-education.com/dictionary .html. "Bondage and discipline (B/D), dominance and submission (D/S), and sadism and masochism $(\mathrm{S} / \mathrm{M})$, also known as BDSM/kink, is becoming an increasingly popular topic in both mainstream media and people's sexual lives." S. Pillai-Friedman, J.L. Pollitt, and A. Castaldo, "Becoming kink-aware, a necessity for sexuality professionals," Sexual and Relationship Therapy 30 (2015), 196-210, p. 196.

4 "Serious leisure" is a useful term first introduced by Robert A. Stebbins, "Serious Leisure: A Conceptual Statement," Pacific Sociological Review 25 (1982), 251-272. 
BDSM-inspired sexual foreplay, everyday sadism and masochism, and commercial pornography: BDSM is a social activity, which is to say the participants share a common view of its definition, rules, and values.

I start by asking what BDSM is and what it is not. Let us pay attention to the dialectical interplay between what is intrinsically desirable and undesirable, like pleasure and pain. I discuss the motivation of and the relevant reasons for BDSM activities, given the enigma of how pain, humiliation, and bondage can be so desirable. The standard view is that the explanation is related to sexual and erotic pleasure, but BDSM enthusiasts may also have deeper personal, cognitive reasons for doing what they are doing. The key philosophical point is this: in the BDSM field many of our normal definitions of terms such as violence, sex, pain, and enjoyment either lose their conventional meaning or become alien, ambiguous, controversial, or essentially contested. This challenges anyone who wants to study this field, a trial that we should not underestimate. It is important to distinguish between two perspectives: insiders and outsiders tend to consider BDSM activities in different light. The outsiders, even when they are knowledgeable, sympathetic, and impartial, may fail to understand the desires, practices, and values of the insiders, that is, the practitioners and their intended audiences. Such a failure is particularly disturbing in the case of power wielders like religious, medical and legal authorities. BDSM is indeed a subversive field and as such it resists attempts of domination and control, even at the conceptual level. It is subversive because, among other strange things, it refuses to respect the accepted standard definitions of pain and pleasure, or jouissance. ${ }^{5} \mathrm{~A}$ BDSM aficionado's ideas of a delightful activity can be difficult to follow. ${ }^{6}$

\section{Tropological Delineations}

Here is an instructive description of BDSM and particularly of sadomasochism or S/M that focuses on "[ $t$ ] he sexual organization of social risk, for one of S/M's characteristics is the erotizing of scenes, symbols, contexts, and contradictions which society does not typically recognize as 'erotic." BDSM is about playing risky games understood as sex between two seemingly unequal partners. Also, BDSM can be seen as "radical sex" that is "our "exploration of eros and the

5 “Pleasure' was associated with extremely intense sensations," E. Faccio, C. Casini and S. Cipoletta, "Forbidden Games: The Construction of Sexuality and Sexual Pleasure by BDSM Players," Culture, Health \& Sexuality 16 (2014), 752-764, p. $75^{2}$.

6 N. Largier, In Praise of the Whip: A Cultural History of Arousal. Tr. G. Harman. New York: Zone Books, 2007 . 
liberation of erotic potential from Puritan ethics."7 This looks like a reference to fetishism: one finds or makes non-erotic goals of desire erotic; this is the kind of fetishism we may call functional because its objects are actions and practices. Often we associate fetishism with things like women's high heeled shoes; this can be called material fetishism, when a fetish is a prima facie nonsexual thing loaded with sexual meaning. In other words, the erotic and the non-erotic switch their places under the umbrella of hazard jointly shared by a top and a bottom. The top dominates the bottom and brings about, say, pain and humiliation for both of them to enjoy.

Next, I will derive a novel key characterization of BDSM, which is, as it is easy to see, closely related to the standard one mentioned above. The main point (of $\mathrm{S} / \mathrm{M}$ ) is that the characterizations of erotic/pleasure and non-erotic/ pain change places, in other words, they exemplify reversible pairs. Hence, in a BDSM context pain and pleasure are related metonymically. ${ }^{8}$ Kenneth Burke writes:

[We]might extend the [metonymic] pattern to include such reversible pairs as disease-cure, hero-villain, active-passive [and] we should "ironically" note the function of the disease in "perfecting" the cure, or the function of the cure in "perpetuating the influences of the disease."

Pain-pleasure is indeed one of such metonymic pairs: the direct function of pain is now to maximize pleasure, which in the $\mathrm{S} / \mathrm{M}$ context seems to be a

7 A. McClintock and B. Thomson, quoted by R.F. Plante, "Sexual Spanking, the Self, and the Construction of Deviance." In Sadomasochism: Powerful Pleasures, P. Kleinplatz and C. Moser (Eds.). New York: HPP, 2006, pp. 59-79, pp. 61-62. It is questionable whether all the forms of BDSM are sexual or erotic, for instance activities that focus on slavery and punishment, as Yolanda Estes says (see n. 19). A masochist who longs for humiliation in the hands of a paid dominatrix because of his deep guilt feelings may not seek sex but some kind of psychotherapy. To call BDSM a sexual field, without qualifications, is mere gloss. It is of course impossible to give a definition of sex or eroticism. They are typically cluster concepts (no necessary conditions of being a sexual content can be found unlike sufficient conditions.) When one calls, say, an activity "sexual" one is displaying a contextual marker around which one can then delineate his discursive intentions.

8 Metonymy is a rhetorical trope that makes two related terms interchangeable, for instance, because they refer to a container and contained. In this case I say "I drank one bottle" when I could have said "I drank one beer." You say, "King William won the battle of Hastings" when you could have said "The King's armies won the battle." In the case of BDSM a product of an activity is sometimes substituted for the activity itself. We say that the "pleasurable sensation" (product) is interchangeable with "the painful flogging" (activity). (See http://examples .yourdictionary.com/examples-of-metonymy.html).

9 K. Burke, A Grammar of Motives. Berkeley: University of California Press, 1969, p. 512. 
positive bodily sensation and in the case of disciplinary or humiliating activity a mental pleasure. Now we can freely alternate "pain" and "pleasure," as in "Whip me, give me pain" and "Whip me, give me pleasure." "Pain" and "pleasure" both refer to one self-identical thing, namely, what I want from this social exchange. No doubt, the rhetorical context is characterized by its metonymies.

Of course, in most narrative fields the relationship of pain and pleasure is far from metonymical, like torture in legal and punitive contexts and hurt in many medical procedures. When we discuss serious pain close to that that of torture, and not some pain-like playful little titillations, this makes the BDSM context a special one: it is a context in which serious pain and rich pleasure are indeed related metonymically in cooperative setting. To make the case stronger, also consensual cooperation between the top and the bottom shows its metonymic features: when you are hurt by an agent this seems like a paradigmatic case of conflict; yet, BDSM is all consensual and hence cooperative. Such a double metonymy strongly characterizes the unique world of BDSM. In the language of BDSM, pain and pleasure as well as conflict and cooperation freely switch places.

If it does not happen in other contexts, this type of metonymy indeed identifies BDSM, and more specifically consensual S/M. I think this is so: the relevant double metonymy is unique to BDSM, but this of course depends on various factors I cannot discuss here. Metonymy, when that is used as a characterization of BDSM, reveals its paradoxical, revolutionary, and truly subversive nature: any social context where conflict and cooperation are related metonymically and $\mathrm{X}$ and $\mathrm{Y}$ also are situated metonymically, when $\mathrm{X}$ is something intrinsically undesirable and $\mathrm{Y}$ is its antonym, is an instance of BDSM. $\mathrm{X}$ and $\mathrm{Y}$ are intended bodily or mental sensations resulting from certain typical social exchange like activities. This applies to everyday masochism, too. If I am begging for punishment and maltreatment, say, in domestic life, I desire it, which makes me a masochist. If I enjoy punishing my subordinates and derive pleasure from it, I am a sadist; I derive pleasure from actions that are not enjoyable as such, or desirable from the point of view of one's audiences. ${ }^{10}$ The difference to BDSM is that an every-day sadistic exchange is never cooperative or consensual. Of course, such a usage of the terms "sadism" and "masochism" may sound odd and perhaps dated today. We may reject the idea of sadistic and masochistic personality types but it is difficult to reject the use of those terms altogether.

Here is an illustration: The top cuts his bottom's skin with a sharp blade making him bleed. This activity combines the horror of free flowing blood, the

10 See for example Jean-Paul Sartre, Being and Nothingness. Tr. H.E. Barnes. New York: Gramercy Books, 1994, pp. 394ff. About the ultimate failure of sadism, see pp. 405-406. 
perceived hazard of being cut as mental pain and panic, and being wounded as physical agony. Next, the bottom reports delight as well as strong pleasurable feelings and sensations. In this case, delight and pleasure are substituted for horror, mental pain and physical suffering, although the bottom can also report unadulterated pain. Hence, the pain-pleasure pair is freely reversible, just as both Plante and Burke (above) say they should be; this is what a metonymic relation means in this definitional context. Burke's additional point about irony comes in as follows: in an everyday context, when I am hurt and someone asks if I am hurt, I can answer -ironically - by saying "What a pleasure this is, don't you see!" To maximize your pleasure by letting someone hurt you, indeed contains an analogous ironic aspect, at least if seen from an outsider's perspective. Indeed, in an $\mathrm{S} / \mathrm{M}$ context irony is clearly visible to outsiders but perhaps not always to the participants themselves. The same can be said of experienced horror and joy: the dedicated audiences of horror films are masochists since they enjoy horror. They often seem to realize this anomaly, or their perception of their own strange sensibilities, which, due to its irony, makes the whole experience even more enjoyable to them. Of course, in such a context the ironic aspect is so strong that the audience may laugh - and they do. Interestingly enough, horror and laughter in such a context come close to being interchangeable. Sometimes this tendency is so strong that the show becomes ridiculous. Notice how irony and metonymy overlap here: what is ironic, that is to laugh at horror, starts looking as an instance of metonymy where laughter and horror become interchangeable. Metonymy and irony always are closely connected. Alas, however ironic the logic of BDSM plays may be, legal and medical authorities have traditionally refused to see it that way; or perhaps they live in denial so deep that it turns into aggression. This could to a degree explain the relevant elites', as non-intended audiences, tendency to reject and also strongly condemn BDSM.

Do the desires of BDSM have their metaphoric meaning, too? The joy of BDSM also is in its metaphors. What is then the metaphoric message of urinating or defecating on a bottom? Such activities beg for metaphoric reading since a metaphor changes the considered context into another one that is only remotely connected to the original and by doing so creates a set of secondary meanings: "Men are nothing but pigs" moves the discourse across the limits of fine social etiquette and the hard facts of the human sciences into that of animal husbandry and its real life smells and sounds. Staci Newmahr says the key metaphor of BDSM is that of life and death. ${ }^{11}$

11 S. Newmahr, Playing on the Edge: Sadomasochism, Risk and Intimacy. Bloomington: Indiana University Press, 2011, p. 184. This is an admirable book that gives a good idea of 
Newmahr may well be right; however, the tropological themes in BDSM can be developed further than that. For instance, anal fisting belongs to BDSM, or we can situate it as a practice in the repertoire of BDsM. ${ }^{12}$ The idea sounds radical, painful, and dangerous, or impossibly repulsive from the point of view of its non-intended audiences. Of course, anal sex constitutes an entire genre of pornography, or the hard core of it, but anal fisting goes one step further along with vaginal fisting. The more demanding idea and practice of anal fisting rests also on a cooperative metonym, on the symbolism of two persons understood as one, connected in a way that cannot be cracked. Why is this different from heterosexual penis-vagina penetration as a kind of bond between two persons? It is different because in many ways it is so much more demanding, just like other BDSM activities. Extraordinary deeds create extraordinary effects. Vanilla sex may make no impression on a couple, unlike such extreme experiences as anal fisting. Just the knowledge that so many people strictly disapprove of it may be decisive. Therefore, we see here a special dialectical interplay between individuality and unity. Yet there must be more to it. If so, what is the relevant metaphor? The mythology of anal unification crosses the limits of its original medical anatomical context in which the main allusion is to stretching of the dry and tight anus instead of the fluid and flexible vagina. Again, irony emerges along with desire and its metonymies: the fluid flex (pleasure) under a fist is substituted for the anus as paradigmatically dry tight thing (pain). Tightness and flexibility now belong to the same context as ironic opposites. Next, our mental representations vacillate between what is real and anatomic, tight anus, and the key metaphoric ideal, an unbreakable bond between two persons. Here we can see an alternative metaphor to Newmahr's life and death, namely that of an unbreakable bond. Of course, we also can view anal fisting in terms of life and death: vagina is for giving life and anus for extracting dead waste. This is almost too obvious, though.

Here the idea of a bond is indeed a new metaphor built on the top of an ironically applied metonymy. There is no bonding in the original descriptive context but now it all, with its perfect plausibility, depends on the secondary

the insider's perspective on BDSM. About D/S, see K. Cunningham, Conquer Me. Eugene, OR: Greenery Press, 2010, 108ff. She makes a crucial distinction between submissiveness and masochism, and consequently, I think, between domination and sadism. For instance Anne Desclos' The Story of O (1954) describes O's submissiveness and not masochism. She does now desire suffering. She says she loves her Master and therefore she submits. The master, however, wants total submissiveness without love.

12 See M. Weinberg, C. Williams, and C. Moser, "The Social Constituents of Sadomasochism," Social Problems 31/4 (1984), 379-389; and C.J. Hale, "Leatherdyke Boys and Their Daddies: How We Have Sex Without Women or Men," Social Text 52/53 (1997), 223-236. 
meaning of bonding as something highly commendable and hence ethically valuable and as such desirable. Such a bond is a pledge with a deep and complex narrative (secondary) meaning ranging from commitment to love. ${ }^{13}$ At the same time one may feel that such a narrative must be false and definitely refuse to recognize how and why one could freely substitute "fluid, pleasant flex under a fist" for "dry, painful tightness." Thus, one misses the awareness and avoids the danger - of the key metaphor of an unbreakable social bond. All this must sound subversive, perhaps even repulsive. The metaphor must then be denied as it is simply too dangerous to bear. It may look like sheer madness and perversity that must be seen as (medically) pathological and (legally) suspect activity. Again, to distinguish between a view from inside and outside is crucial: outsiders may be able to see the rhetorical construction of the key metaphor and assent to its basic validity but the participants live it. Without such a metaphor, say, anal fisting functions like sheer violence, when it in reality is full of meaning. BDSM activities may not be about raw animal pleasures.

Here is then my amended characterization of BDSM: By BDSM we mean (more or less openly) sexualized social activities where a pair of mental predicates like pleasure and pain can be freely substituted one for the other (metonymy), these predicates being mutually incompatible in their standard contexts (irony), and they are charged with shared meaning (narrative) based on metaphoric shifts of their fields of discourse. All this takes place in a cooperative context that can and normally is called a conflict situation, which is another source of metonymy here. Here we see the two opposites, life/death and pleasure/pain, constantly meeting and departing at the symbolic level. ${ }^{14}$ Hence, the metonymic aspects of S/M focus on the interplay of two bodily feelings and sensations, pain and pleasure, whereas at the metaphoric level we look across borders and find, say, a player reporting experience of purification, discovery of one's true self, or her seamless unification with another person, her top or bottom - seeing "fresh light and value" in the world beyond this one. One may indeed mention the symbolisms of life and death within BDSM, like Newmahr says; they are the key metaphors. For its non-intended audiences BDSM may well mean the open gates of hell and the abyss of damnation, perhaps this is so for a true edge player as well; but then their background narratives are radically different.

13 On narrativity and narrative meaning, see G. Genette, Narrative Discourse. Tr. J.E. Lewin. Ithaca, NY: Cornell University Press, 1980, pp. 25-26.

14 On death and sex, see G. Bataille, Erotism: Death and Sensuality. Tr. M. Dalwood. San Francisco: City Lights Books, 2001; also E. Scarry, The Body in Pain. New York: Oxford University Press, 1985 . 


\section{The Riddles of Motivation}

The field of BDSM is large and fantastically varied. Its borders are fuzzy and much of it is hidden and secretive, or made to look like pornography. The field is enclosed in abjuration, moralism, misinformation, and myth. For philosophical argument's sake, let us simplify the field as follows: a BDSM participant (bottom) enjoys pain, punishment, humiliation, and bondage; according to the definition of BDSM above the participants successfully transmute them into pleasure, respect, and even liberty - this looks like some miraculous psychological alchemy. However, if the participants, especially the bottoms, do not find their desire for pain, humiliation, and bondage somehow rewarding, they would not consent to playing these roles. ${ }^{15}$ It is not possible to say "I enjoy pain" and to mean it literally: pain is not an object that can be enjoyed as such. Yet, the logic of the play here presupposes the mental pain/pleasure transmutation in question, no doubt about it. But how is it possible? Pain as such cannot be pleasure. It is logically inconsistent to maintain pain to be pleasurable. (We discuss now the logic of some psychological concepts, not their rhetorical usage like we did above.) This problem makes BDSM, and especially S/M, a supremely interesting case from the point of view of psychological hedonism in philosophy, which is a topic as old as philosophy itself. ${ }^{16}$

The standard view of pain is that it is a distressing, paradigmatically disagreeable bodily sensation, and a highly motivating mental state. Moreover, it is logically inconsistent to say something like this: I feel exactly the same pain as yesterday but now it does not feel so bad. In the same way, it is inconsistent to maintain that I still have the same pain but, say, that my medication makes it easier to tolerate. In other words, I cannot doubt that I am in pain. ${ }^{17}$ If I tolerate pain better the pain is now less severe. Pain is pain, a raw sensation, and that is all; yet, an S/M bottom may say he enjoys it when whipped hard with a singletail. The pain can be close to intolerable and he may exhibit all its relevant behavioural pain symptoms but he says he somehow enjoys it. Does he really enjoy pain? How is this to be understood? Does it mean that he did not experience severe pain, for instance, because he was so highly stimulated by the activity in question? Sometimes positive excitement, mind control or, say,

15 T. Schroeder, Three Faces of Desire. New York: Oxford University Press, 2004, p. 66.

16 See D. Wolfsdorf, Pleasure in Ancient Greek Philosophy. Cambridge: Cambridge University Press, 2013 .

17 P.S.M. Hacker, "On Knowledge and on Knowing that I Am in Pain" (http://info.sjc.ox.ac .uk/scr/hacker/docs/Knowledge\%2oof\%2oPain.pdf). It is logically speaking nonsense to say something like "I doubt I am in pain" when I show all the relevant pain symptoms. 
sexual arousal works like a pain-killer: "Campanella [...] could so abstract his attention from any sufferings of his body, that he was able to endure the rack itself without much pain [...]."18

Someone may then ask, can excitement also explain why one enjoys pain? Perhaps you can talk about the delight the situation brings about instead of physical pleasure? How to explain the excitement as a kind of delight then? Certainly it is not the case that excitement creates an altered bodily state where the pain itself becomes enjoyable - one cannot enjoy pain as such. Hence, the bottom feels the pain but also somehow enjoys both the situation where it is delivered and his relation to the top. For instance, a love bite hurts but because it is a love bite it is also enjoyable: it says she loves me. In this example, pain, or pain-and-love, is pleasant because of its relation to love. However, it is impossible that pain would be enjoyable as such; pain is not its own reward.

We know that certain somatic perceptions are a mixture of pain and pleasure, as reported for instance by marathon runners. Such mental states are mixed pleasures. Hence, in S/M pain plays the bottom may at the same time feel pain and report enjoyment or delight as interconnected and mutually synchronized feelings. It is possible that the bottom feels two separate sensations, physical pain and pleasure, but the pleasure is so strong that the pain can be (to some extent) neglected. In this case pain is not pleasure but pain and pleasure arrive as if side by side both having their own causal genesis. Pain and pleasure in S/M are, as I see it, two different and separate sensations that emerge and vary together in such a synchronized manner that it is natural to conflate them in personal reports. Just like the love bite really hurts and it feels good but it is the bite that hurts and feels good; we should not say the pain feels good when the bite feels good. In the same way whipping may feel good and delightful even if we refrain from saying that the associated pain feels good. It is crucial to ask what exactly feels good and what is delightful.

Let me illustrate the explanations given above by means of two rather disturbing semi-pornographic examples of BDSM play performed in front of an audience and shown on the Internet. Two naked, good looking young women are tied together from their left wrists by a rope two feet long. Both have a singletail whip in their right hand. They lash each other tit-for-tat as hard as they can. They tremble, grimace, scream, cry, and weep showing all the bodily symptoms of real pain, which clearly is extreme. Each lash leaves a bright red mark on the skin. They go on for a long time. A second example: This is a competition to determine who lasts longer. Two naked young women (bottoms)

18 E. Burke, A Philosophical Enquiry into the Sublime and Beautiful. Ed. P. Guyer. Oxford: Oxford University Press, 1757/2015, pp. 53, 106. 
lie down on a platform on the belly; we can see their faces but nothing else. We hear the whip and the blow. The women are clearly scared of what will happen to them. Behind them stands a whipper (top) with a heavy singletail whip. He lashes them one after the other and commands them to count the strokes aloud. We see that the pain is absolutely overwhelming, like torture, and the women really agonize. In this situation, pleasure of any type is out of the question. One surrenders, they both stand up, and the top comes to the front and congratulates them - very sternly, devoid of any sympathy at all, and then walks away. The audience applauds. Here we have a case of pure and real pain and pain behaviour with no hint of enjoyment, pleasure, sex, or eroticism. These women are afraid, not visibly eager, and certainly did not show any signs of enjoyment at all. At the same time, they do not look like being coerced to do what they do. ${ }^{19}$ Yet, I must admit that coercion looks like the most plausible explanation here.

Pain and suffering may indeed have their sacred and cathartic quality. Religious asceticism tends to recommend them. Religiously meaningful torture like self-flagellation has its rich and lasting heritage, extending from the Egyptian cult of Isis to the Dominican order. ${ }^{20}$ It is clear that in these cases pain is accompanied by one's own, deep sense of reward and feeling of satisfaction, which is motivating. Again, pain is not its own reward although the reward is not possible without the self-inflicted pain; this is what the flagellant believes. He certainly is no hedonist. Hence, BDSM is not necessarily about sensory enjoyment as such. It is deeply related to higher cognitive and emotional functions. According to this view, when you freely suffer humiliation and bondage and risk your health, you will emerge from that situation as a renewed person. ${ }^{21}$ At its best, it is a life-altering, other-worldly experience that is as rare as it is personal, a truly remarkable achievement. In this way we can argue against the hedonistic model of BDSM and in favour of a cognitive model. ${ }^{22}$ Analogously, we may mention disgusting pleasures: a person feels deep

19 Newmahr (2011) emphasizes intimacy as the true reward, see p. 186: "SM is about creating intimacy through social interaction." Yolanda Estes seems to agree; see her "BDSM: My Apology." In Desire, Love, and Identity, G. Foster (Ed.). New York: Oxford University Press, 2016, Chapter 8.

20 See J. McCabe, The History Of Flagellation. Whitefish, MT: Kessinger, 2007; and R. Pearsall, The Worm in the Bud: The World of Victorian Sexuality. Harmondsworth: Pelican Books, 1971, Ch. 7 "Perversion." Pearsall pays special attention to English public schools.

21 On professional dominas, see H. Smith and C. Cox, "Dialogue with a Dominatrix." In $S$ and M, Studies in Sadomasochism, T. Weinberg and G.W. Levi Camel (Eds.). Buffalo, NY: Prometheus Books, 1983 .

22 The cognitive model emphasizes the participants' beliefs about the activity. These beliefs motivate and justify the activity. A participant reports, "I love to play because I want to see 
pleasure when he has reason to feel bad about the pleasure in question. This is a common experience but no one would say that the pleasure itself is disgusting - pleasure is pleasure and the reasons for being disgusting are another thing. One simply feels pleasure that is accompanied with disgust; this is to say, there are no disgusting pleasures, only reasons for thinking that some pleasures are disgusting and then the relevant negative feelings will follow. Many people enjoy pornography in such a conflicted way.

These reflections apply primarily to the bottom; perhaps they also apply to the top, but in her case the key term must be power. ${ }^{23}$ We know that wielding power is often stimulating and enjoyable, sometimes ecstatically so. When we notice that the top in his sadistic role is not able to enjoy any direct sensory pleasure, we conclude that he works hard for some rewarding and satisfying beliefs and ideas of personal and social supremacy and power. Here we must keep in mind that tops and bottoms may switch their roles and hence utilize all the opportunities inherent in BDSM. There is another consideration that deserves to be mentioned: it is undeniable that people are strangely fond of witnessing other persons' pain, suffering, and death - in these days mainly but not solely in fictional terms. Somehow this stimulates and fascinates us no end, as our contemporary popular culture so amply proves. ${ }^{24}$ We want to see it and so it must somehow be rewarding. Violence and its victims are in the core of popular entertainment, war and mayhem sell well, and the raped and tortured body in its various forms is viewed with the superbly enjoyable mixture of horror and enthralment. Can this psychological fact explain the top's sadistic motivation? Perhaps it can. Perhaps this interest in violence and pain also is connected to power: when I view another person's pain it empowers me, as if the victim were suffering in my hands. Yet, as a spectator, I am not responsible, I am innocent, I cannot be blamed for the other person's suffering; so I am free to enjoy it as if I were supremely powerful, so powerful that no moral norms may touch me. This is what the top achieves, too.

Let me next address very briefly humiliation. For many BDSM participants, humiliation seems to be a form of respect. This again sounds paradoxical but can be tentatively explained as follows. In their mutual social situation tops and bottoms are engaging in a relationship where they feel for each other

what is deep within each of us." (Newmahr, 2011, p. 173). To play is to explore, which has little to do with direct sensual stimulation like bodily pleasure or even with sex. Faccio, Casini and Cipoletta, 2014, p. 753. Power derived pleasures must be cognitive-emotional, not physical. 
and share their mutual respect and intimacy; in other words, they freely cooperate, which entails respect regardless of what they happen to do. The top is supposed to care for her bottoms; hence, she would not serve that evil trinity, or pain, humiliation, and bondage, raw to her bottoms. They all know what humiliation entails in everyday life but in BDSM play the top is supposed to respect her bottom and she shows it by humiliating him - this may well be the point of the activity. We just need to understand respect in a special way, when it depends on humiliation. My argument is as follows: Suppose the top respects the bottom. Next, the top humiliates her. The top shows his respect by means of humiliating her; it does not do to say, the top shows his respect along with humiliating her. Again we meet a metonymical relation between humiliation and respect, as my key characterization of BDSM requires: humiliation and respect mean the same thing. When we move over from tropological consideration to psychological mechanisms we may then suggest that humiliation and respect are related instrumentally, that is, humiliation brings about or creates the sense of respect. Anyway, "humiliation" and "respect" are freely substitutable terms in this context.

\section{Sade and Sadism}

We must draw a firm conceptual distinction between a BDSM top and a bona fide sadist, or a habitually cruel and cold person, and his typical sources of enjoyment. The usual image of sadism and masochism is dominated by ideas that do not correspond to social and consensual BDSM activities but rather reflects the ideas of the Marquis de Sade. Therefore, it may be useful to clarify this background. ${ }^{25}$ In BDSM, the top, although she enjoys and exploits her dominant position, at some level also wants to please her bottom and enjoys an intimate and respectful relation with him. Yet, her identity can be that of a sadist because she enjoys hurting the bottom. However, a sadist in Sade's sense rejects all this and intends to exploit, belittle, humiliate, subjugate, hurt, and harm a victim, ultimately aiming at his death. Let us briefly pay attention to certain aspects of Sade's novels, such as Justine, Juliette, and The 120 Days of Sodom, to understand this better. ${ }^{26} \mathrm{He}$ often describes what can be called plays or games between sadists and their victims arranged in the form of ever changing, diverse illustrative vignettes. ${ }^{27}$ It all happens as if on theatre

\footnotetext{
25 See for instance (https://www.academia.edu/11723094/The_history_of_sadism_and _masochism_).

26 See T. Airaksinen, The Philosophy of the Marquis de Sade. London: Routledge, 1995.

27 R. Barthes, Sade, Fourier, Loyola. Tr. R. Miller. London: Jonathan Cape, 1976, pp. 154ff.
} 
stage - Sade wanted, unsuccessfully, to be a playwright. A sadistic libertine brings in a victim or group of them and the action may start. Often it takes the following cyclic form: philosophical reflection - sexual arousal - torture - sex killing - discharge of energy in ejaculation - exhaustion; and then back to philosophical reflection and dialogue.

This idea of the repetitive circle of libertine life works as follows. The heroes are philosophers who discuss and theorize pleasure, sex, beauty, virtue, religion, power, and death. This offers them new ideas and stimulates them, which leads them to attack their victims by torturing them, then having forced sex with them, and often killing them. Here murder is the highest and most natural form of voluptuousness. Sex in itself is a rather mechanical act in the sense that the heroes, men and women, discharge like a loaded gun when one pulls the trigger. It also is clear that the heroes are never intimate with their victims; on the contrary, they isolate, violate, and harm them as the Other and in as many ways they ever can invent. The victims are nothing but victims mostly without face, character, personality, or individuality. They are expendable to the degree that they almost do not count as living human beings; yet, their sufferings are - rather strangely - supposed to be meaningful and as such stimulating and enjoyable. Sade's 120 Days of Sodom is actually a summa of all vices in the realm of sex and sexuality: nothing is left unmentioned and the heroes do try it all. ${ }^{28}$ They are, therefore, paradigmatic non-consensual sadists who play their deadly games with their helpless and often faceless victims who certainly are not masochists. Sade justifies all this under the banner of total freedom and full enjoyment of the supreme pleasures of life. His oeuvre is a catechism of freedom in the condition of nature, or alternatively, a display of pure, unmitigated subversives at any cost. However you want to read it, Sade plays with his twisted reason and lethal love in the name of the game of sex and pleasure. He wants to make the most destructive form of sadism the cornerstone of his world-view: the sole source of pleasure that is strong and exciting enough for free and resourceful persons. Such is the story of wild and varied, atavistic, theatrically staged sexual rage.

It is naïve to think that the roles of tops and bottoms would automatically complement each other - without a paradox - because a sadist cannot torment the victim who obviously enjoys and desires the punishment, which then makes the sadist unhappy. A Sadian sadist needs a helpless, reluctant, struggling, suffering, and unhappy victim. The problem is that the masochist does not suffer in the required and desired manner. He is not avoiding pain and humiliation as he should; on the contrary, he gravitates towards it. For a sadist 
this does not do. Therefore, a masochist cannot find himself a bona fide sadist, they will refuse to serve. Hence, he needs situations where some unsuspecting person torments him, not quite knowing or caring of what he or she is doing. A masochist must find his own Venus in Furs who, while not a sadist proper, is sufficiently resilient, cruel, cold, and demanding to satisfy his hidden desires. This is what Leopold von Sacher-Masoch communicates to his readers. ${ }^{29}$ In his novels, masochists do not desire physical pain but some rather sophisticated forms of humiliation, mental suffering, and anguish. For example, a man longs for his loved one who persistently neglects and demeans him. She is there for him (as an ideal object of desire in de dicto sense) and at the same time she is not (as an individual person, or de re). This is what the man ultimately desires even if he begs her to change her behaviour. If she did, his love life would flop. Hence, a masochist struggles in a context he both hates and enjoys at the same time finding all that disgrace deeply meaningful. It is his desire's essence and he hates it. This may look like Teasing-and-Denial but it is not: the love-object, the woman, does not play the game designed by the masochist as a victim; on the contrary, she plays no games. If she were, she would be giving something to the victim, the next move, which a cold and cruel person would never bother to do. She is not enjoying it; she could not care less. Both Sade and SacherMasoch write fiction, though. The point is that the characters they created are very different from those of the persons playing in the field of BDSM, who engage in these activities in a genuinely free and consensual manner.

\section{Problems with Consent}

Consent means that some persons as rational agents freely agree to act in some way that is supposed to co-ordinate their actions and satisfy their desires either jointly or individually. In this sense, consent means social co-operation, or a starting point of joint action. It is easy to see why consent is important in such a context as BDSM where the activities can be so unusual, dangerous, controversial, and subversive. Consent or co-operative agreement between a top and his or her bottom is important also for moral reasons. Without consent the bottom can, with justification, blame the top for violating him and causing him unnecessary and ultimately unwanted suffering. In other words, consent turns the BDSM scene into a co-operative game, which then protects the participants against negative legal consequences. We can then ask whether

29 See G. Deleuze, Coldness and Cruelty, and L. von Sacher-Masoch, Venus in Furs. Tr. J. McNeil. New York: Zone Books, 1989. Deleuze also writes about Sade. 
such consent should be explicit or is merely implicit consent sufficient. This is difficult to determine in any unequivocal manner. However, the problems of consent are crucially important when we discuss the moral aspects of BDSM.

The moral problems of consensual BDSM depend on the acceptable limits of consenting: it is obvious that a person, in normal circumstances, is not supposed to be able to genuinely consent to everything that may be done to him or her. I cannot give you a morally or legally valid permission to kill me. Another relevant example is a slave contract. Now, the bottom agrees to stay on leash and wear a dog collar, obey and serve the top without asking any questions. Disobedience is severely punished and the slave can be auctioned away. In this sense, the bottom is supposed to be the top's private property. Of course, according to traditional natural law, slave contracts are forbidden; in the positive law they are unknown, but a discipline-oriented couple may well agree on such a contract. The main question is, of courses, how seriously all this should be taken. If it is just play-acting it may be justifiable but it also can be taken seriously - it is, however, difficult to say how seriously.

In certain situations, trivially enough, if drugged or coerced, a person's consent is invalid. If the person is mentally unbalanced her apparent consent is again invalid. In such cases, it cannot entail a valid permission to act on him or her. The problem is that consent should be free but it is not free if the person is mentally unbalanced, drugged, or coerced. In the case of mentally unbalanced persons it is difficult to verify that they know both what they are consenting to and what the consequences of their consent are. Their apparent consent is not properly informed. It follows that that a valid consent entails sufficient information and correct beliefs. You must not be cheated or mislead to consent. Such an information requirement is a complex issue we must neglect here. ${ }^{30}$

Some situations may be too dangerous to allow for consenting. ${ }^{31}$ For example, someone who finds breath control or choking play personally acceptable, desirable, rewarding, and exciting might consent to her partner making her faint by the lack of air. However, this may lead to death by asphyxiation and then it is unclear whether the top is morally and legally responsible. Two things can be said to contest such dangerous consent: it might be claimed that the consent is invalid because it is possible that certain consequences are risky

3o See Nir Eyal "Informed Consent," The Stanford Encyclopedia of Philosophy (Fall 2012 Edition), Edward N. Zalta (ed.), URL = <http://plato.stanford.edu/archives/fall2012/entries/ informed-consent/>.

31 For a legal interpretation of this maxim, see C. White, "The Spanner Trials and the Changing Law on Sadomasochism in the UK." In Kleinplatz and Moser, 2006, pp. 167-187. See M. Stocker, "Desiring the Bad: An Essay in Moral Psychology," The Journal of Philosophy LXXVI (1979), 738-753. He argues that one may (rationally) want to hurt herself. 
but inadequately understood or appreciated by the bottom. At this stage her mental stability and competence may be re-evaluated. However, given that the bottom is risk-aware, informed, and mentally competent, it may be difficult to argue that the consent is invalid even though the activity in question were uncommon, disgusting, hard to comprehend, and seriously risky. After all, many commonly accepted social activities are seriously risky as well, for example, extreme sports. In professional boxing the fighters agree on a common but mutually exclusive goal of incapacitating the other by violent means. No charges have been pressed even after a death in the ring. Why should BDSM be different, as it in a legal perspective in fact is? The answer may well be: boxing is a fully institutionalized self-regulating activity with its own well-understood rules and norms, unlike BDSM that is just an informal field of dangerous activities. BDSM is thus compared with bar-room brawling rather that professional boxing. Whether this is a justified legal and moral idea should be reviewed critically. An attempt to protect a consenting, competent adult from herself, or from taking too serious risks, is paternalism, which is unjustifiable in a liberal moral framework. ${ }^{32}$

Now, a logical impasse may emerge. Suppose I think an S/M activity is dangerous and repulsive. I infer it is impossible that anyone would like to participate in it freely and consensually. Justified by this key premise, I argue that the participant indeed is unfree, mistaken, and somehow coerced; hence, his apparent consent is invalid. Such faulty but such frequently exploited reasoning should not be taken seriously. It is, anyway, possible that you freely desire something that is incomprehensible to me and my social reference group. It is argued, from an outsider's perspective, that when the risks of a BDSM activity are high and the activity in question somehow strange and disgusting the consenting person cannot be mentally normal. It cannot be normal to consent to that type of activity because any suggested motive to participate in it is incomprehensible. In other words, the outsiders, as a non-intended audience, refuse to understand the insiders' life projects and the related reasons for action.

However, this way of thinking is question begging if there is no independent evidence for mental problems. What must be scrutinised is whether the person is in fact mentally damaged because, say, he or she was sexually abused as a child. However, the same is not done in the case of professional boxers. This may, anyhow, explain in a seemingly valid way the strange desires as pathological symptoms and thus allow us to dismiss consenting. A person's pathological state undermines his personal responsibility and voids his explicit consent. However, to do so we need first to verify the existence of psychological damage

32 See H. Häyry (Gylling), The Limits of Medical Paternalism. London: Routledge, 1991. 
and then prove that it and not something else is the cause of the unacceptable behaviour in question. This is seldom possible. Ideally we should be casespecific: this requires us to show that given damage $\mathrm{X}$ one will indeed later on demonstrate unrealistic, sexually relevant risk acceptance; moreover, we should also show that all or at least most who suffer from $X$ would do so. There should not be $\mathrm{X}$ sufferers who do not display BDSM symptoms. The problem is that so many children are maltreated, so many have mental problems, and yet so few love BDSM. The key term is accurate prediction: does $\mathrm{X}$ reliably predict BDSM and only that? Accordingly, we should find a special type of X that accurately predicts and explains BDSM. It is not easy to show that exactly this specific damage causes the allegedly abnormal behaviour exhibited in BDSM activities. Without verifiable, detailed information about the history and causes of the relevant mental problems, all these so-called explanations are nothing but thinly veiled character assassinations. Moreover, from the fact that damage $\mathrm{X}$ predicts BDSM, it does not follow that BDSM is intrinsically undesirable or socially unacceptable - simply because $\mathrm{X}$ is involved.

\section{Safe and Sane?}

BDSM play is, or should be, safe and sane - as the standard insiders' saying goes. ${ }^{33}$ The ideological mantra is something like the following. Its deep ironies are easy to appreciate: the players enjoy activities that are supposed to exemplify the paradigms of blood, horror, pain, and danger, whose key metaphors are said to be life and death; yet, it all should be safe and sane. How can that be? Here the ironic aspect is created by the reference to safety when the play is supposed to appear as unsafe as possible, at least at the symbolic level. Now pain play starts looking like mere teasing, domination threatens to collapse into play acting, humiliation is based on pretending, and slavery becomes an innocent domestic role. We can say BDSM becomes gentrified. Such ironies create a tension within the whole field of BDSM: can it be taken seriously? Here is its secondary irony, BDSM must be made palatable to its unintended audiences, and especially to those social elite power wielders who may ban the whole movement; in other words, the ultimate expressions of subversion become the expressions of something like safe and sane practices. Under these conditions, why would the insiders bother anymore?

Somehow something must be done to make the play as safe as possible, without compromising its inherent excitement. The basic rule is, no permanent 
personal harm or injury may ensue. Therefore, safe words are used; these are part of the consent discussed above. They are specific code words whose utterance stops the play. Notice, that the bottom may scream and plead for the top to stop, which he is not going to do if the magic safe word is not uttered. When pain or humiliation is too much to take, uttering the safe word saves the bottom. As I said above, this pre-empts the whole idea of $\mathrm{S} / \mathrm{M}$ play, if it is to be taken seriously. It is easy to see that this kind of soft ideology can and must be challenged. Therefore, safe words are not always used, namely, if they are against the very idea of the play, in this case edge play. Of course, a play without a safe word can and will be genuinely dangerous, but some players insist on it, that is edge players, or those who participate in the most dangerous games, such as mock hangings or severe beatings, without subscribing to the normal code of "safe, sane, and consensual." 34 Perhaps the last condition, consent, is also the last one to disappear. When it is gone, the action is no longer a play, as it becomes real and all its inherent irony is gone as well. This is to say that without its ironies, BDSM is not what it is supposed to be. Irony is its essential feature or otherwise we will meet the shadow of the Marquis de Sade. The tropological landscape changes when the essential irony is replaced by the romance of self-destruction, impossible threats, and mortal danger at the edge of the abyss of horror. Tropologically, we move over from the mundane realms of metonymy to the ever fascinating depths of metaphor, from what is merely dangerous and subversive to what is criminal and sick.

Edge players may try and save their face by arguing that all that is required is that both players, the top and the bottom, understand the shared risks of the activity, or they are fully risk aware. ${ }^{35}$ "Sanity" now means risk aware, which represents the last vestige of consent in this context. Without risk awareness the bottom does not know what she is doing; she has no free will. Without it you have a bottom who is a mere victim to be violated at will by all powerful tops in the true Sadian manner. The lack of a safe word certainly makes the play more exciting and, what is important, more genuine, not only an "asif" play of pain and pleasure. I mean, without a safe word the play becomes more real and convincing, or less imaginary but also less metaphoric. This last point seems to contradict what I said above. Now, tropologically speaking, if a safe word tolerates $\mathrm{S} / \mathrm{M}$ 's metaphors, the lack of it certainly signifies its return to metonymy, to raw reality. As Newmahr says, S/M is about life and death, first as symbols and now as a real possibility. You no longer play with the idea of death, you love and live it. The apparent contradiction between my two

34 On edgework, see Newmahr, 2011, Ch. 7 .

35 This is RACK (risk aware consensual kink), see Newmahr, 2011, p. 147. 
accounts of the tropology of edge play can easily be reconciled as follows: its deeper metaphoric aspect is available only to the participants and their intended audiences whereas the unintended audiences stay at the level of reality and its harsh and trivial metonyms; in fact, this is where the accusations of pathological desire and criminal activity make their entrances. The metaphors become exclusive and incommunicado. Accusations of perversity and threats of punishment quickly ensue as the non-intended audiences wield their power to protect their own threatened sensibilities. What is subversive should not be taken lightly, or even mentioned in vain. What is called perverse represents dismay and panic when it comes too close. 